06

\title{
Влияние предварительного ионизирующего облучения энергонасыщенных материалов на чувствительность к воздействию сильноточного электронного пучка
}

\author{
(C) Г.Г. Савенков, ${ }^{1}$ В.А. Морозов, ${ }^{2}$ М.А. Илюшин, ${ }^{1}$ В.М. Кац ${ }^{2}$ \\ ${ }^{1}$ Санкт-Петербургский государственный технологический институт (технический университет), \\ 190013 Санкт-Петербург, Россия \\ ${ }^{2}$ Санкт-Петербургский государственный университет, \\ 199034 Санкт-Петербург, Россия \\ e-mail: sav-georgij@yandex.ru
}

(Поступило в Редакцию 29 декабря 2017 г.)

Проведено исследование чувствительности двух типов энергонасыщенных материалов (состав ВС-2, представляющий собой энергонасыщенное металлонеорганическое соединение с незначительными добавками полимерного связующего и энергонасыщенный композит NCP с добавлением фуллерена), подвергнутых предварительному облучению потоком $\beta$-частиц и $\gamma$-квантами к воздействию сильноточного электронного пучка наносекундной длительности. Проведенное исследование показало, что предварительное облучение потоком $\beta$-частиц или $\gamma$-квантами энергонасыщенных материалов приводит к существенному увеличению их чувствительности к воздействию сильноточного электронного пучка наносекундной длительности. При этом облучение $\gamma$-квантами более эффективно по сравнению с облучением $\beta$-частицами. Эффект облучения образцов, связанный с повышением их чувствительности к воздействию электронного пучка, сохраняется не менее восьми месяцев.

DOI: 10.21883/JTF.2018.07.46176.2617

\section{Введение}

Интерес к исследованию влияния облучения на свойства и чувствительность энергонасыщенных материалов (ЭНМ) к воздействию внешнего инициирующего импульса возник с конца 60-х годов прошлого века $[1,2]$. Заманчивость предварительного облучения ЭНМ связана с тем, что в веществе под действием ионизирующего излучения начинают эффективно генерироваться реакционно-способные частицы (ионы, электроны, дырки, свободные радикалы, возбужденные атомы и молекулы), что изменяет электрофизические характеристики материалов, и возбуждаются химические или физикохимические превращения (так называемый радиолиз вещества), под действием которых может происходить в том числе и эволюция микроструктуры вещества.

Кроме того, радиолиз ЭНМ при одновременном тепловом воздействии может привести к запуску ускоренного радиационно-термического разложения при температурах примерно на $50^{\circ} \mathrm{C}$ ниже обычного термического разложения [3]. В указанной работе этот вывод был подтвержден на ряде инициирующих взрывчатых веществ (ИВВ) и нитроароматических соединениях (в частности, на пикрате калия). В работе [2] аналогичный вывод сделан относительно перхлората аммония, а в работе [1] установлено, что предварительное облучение пучком электронов с энергией $1.6 \mathrm{MeV}$ резко повышает термическое разложение перхлората аммония. Действие такого же пучка на смеси перхлората аммония с горючим приводит к снижению температурного порога устойчивого горения со 160 до $80^{\circ} \mathrm{C}$. В работе [4] также были получены экспериментальные данные, свидетельствующие о существенном снижении термической стабильности перхлората аммония, но уже после предварительного $\gamma$-облучения.

Особый интерес вызывает изучение влияния предварительного ионизирующего облучения на чувствительность ЭНМ к импульсному электрофизическому воздействию сильноточного электронного пучка (СЭП), что связано с возможностью снижения энергетических параметров пучка и, как следствие, использование для инициирования с помощью СЭП взрывчатых превращений (ВП) в ЭНМ. Возможность снижения параметров пучка может быть обусловлена различными причинами, например тем, что, как уже говорилось выше, изменяются электрофизические характеристики ЭНМ (электропроводность, тип проводимости, концентрация, подвижность и время жизни носителей заряда [5]), а также тем, что возбуждение взрывчатых превращений (в частности, горения) с помощью СЭП с минимальными энергетическими параметрами пучка зависит от значения температуры вспышки ЭНМ. Чем ниже температура вспышки, тем больше вероятность возбуждения быстрых экзотермических реакций [6,7]. А радиолиз энергонасыщенного вещества и может привести к снижению температуры вспышки (см. выше).

В работе [8] была показана возможность управления чувствительностью к воздействию СЭП представителя ИВВ - азида серебра путем предварительной радиационной обработки. В работе [9] было показано, что предварительное облучение потоком $\beta$-частиц энергонасыщенных материалов на основе пикрата калия или свин- 
цового сурика приводит к существенному увеличению их чувствительности к воздействию СЭП наносекундной длительности. В этом случае возможно инициирование ЭНМ без дополнительного воздействия катодного факела (КФ) (понятие о КФ и его параметрах приводятся в [9-11]). В работе было отмечено, что чем выше предварительно поглощенная энергонасыщенным материалом доза $\beta$-облучения, тем выше его чувствительность к воздействию импульсного электронного пучка.

Однако в работе [9] был использован только один вид облучения - $\beta$-частицами, и воздействие электронным пучком проводилось только через $24 \mathrm{~h}$ после облучения. А именно не было установлено влияние воздействия других видов облучения - $\alpha$ - и $\gamma$-частицами и временное действие эффекта облучения (иными словами, нет ответа на вопрос: каков срок жизни реакционноспособных частиц). Так, если проводить аналогию с радиоэлектректным эффектом, то, например, во фторсодержащих полимерах под действием электронного пучка заряженное (электретное) состояние сохраняется при комнатной температуре десятки лет [12]. В то же время в работе [13] установлено, что при достаточно больших дозах $\gamma$-облучения (до $200 \mathrm{kGy}$ ) молекулярная структура полиметилметакрилата становится неустойчивой, и количество радикалов после трех месяцев хранения на воздухе резко уменьшается, а после двух лет влияние облучения исчезает вовсе.

Поскольку облучение $\alpha$-частицами не представляется перспективным из-за их малого пробега в веществе [14], то в настоящей работе были проведены исследования, связанные с влиянием сроков хранения образцов ЭНМ после облучения $\beta$-частицами и с влиянием облучения $\gamma$-частицами ЭНМ на их чувствительность к воздействию сильноточного электронного пучка наносекундной длительности.

\section{Энергонасыщенные материалы и методика исследований}

В исследовании применялись два типа энергонасыщенных материалов: состав ВC-2, представляющий собой энергонасыщенное металлонеорганическое соединение с незначительными добавками полимерного связующего, и энергонасыщенный композит NCP (80 mass.\%) + $+\mathrm{C}_{60}\left(20\right.$ mass.\%) $\left(\mathrm{C}_{60}-\right.$ в данном случае фуллерит на основе фуллерена $\left.\mathrm{C}_{60}\right)$. Средний размер применяемых фуллеритов 30-50 nm. Соединение NCP амминат кобальта (перхлорат (5-нитротетразолато- ${ }^{2}$ ) пентааминкобальта (III) с акцепторным заместителем) (плотность кристаллов NCP $\rho_{\exp }=2.03 \mathrm{~g} / \mathrm{cm}^{3}$ ). Отметим, что соединение NCP обладает пониженной чувствительностью к разрядам статического электричества (по сравнению с традиционными ИВВ). Удельное объемное электрическое сопротивление $10^{12}-10^{13} \Omega \cdot \mathrm{m}$, т.е. данное соединение, является классическим диэлектри- ком. Состав ВС-2, как и все металлокомплексы, обладает полупроводящими свойствами.

Композиция NCP (80 mass.\%) + $\mathrm{C}_{60}(20$ mass.\%) была выбрана по той причине, что ранее в работе [15] была установлена ее бо́льшая энергетическая эффективность при взрывчатом превращении, которое происходило при совокупном действии сильноточного электронного пучка и катодного факела.

Энергонасыщенную композицию $\mathrm{NCP}+\mathrm{C}_{60}$ получали следующим образом: $200 \mathrm{mg}$ смеси 80 mass.\% NCP и 20 mass.\% графена (160 mg NCP + $40 \mathrm{mg}$ графена) помещали в небольшую стеклянную колбу, заливали $20 \mathrm{ml}$ толуола и помещали внутрь заполненной водой ультразвуковой ванны „Сапфир 3404“ (частота ультразвукового генератора $35 \mathrm{kHz}$, мощность генератоpa $50 \mathrm{~W})$. Ультразвуковое перемешивание суспензии производили в течение $120 \mathrm{~min}$. Полученную суспензию помещали в чашку Петри, испаряли растворитель при комнатной температуре досуха. Сухой осадок дополнительно перемешивался тефлоновым шпателем и высушивался при температуре $60-70^{\circ} \mathrm{C}$ в термостате в течение $30 \mathrm{~min}$ для удаления остатков растворителя. Так как толуол мог частично растворить фуллерены, то после испарения взвешиванием контролировали массу полученной композиции. С высокой степенью точности ее масса всегда совпадала с суммой масс исходных компонентов. Полученную таким образом энергонасыщенную смесь использовали в дальнейшей работе.

Bсе энергонасыщенные материалы запрессовывали в колпачки с внутренним диаметром $4.5 \mathrm{~mm}$ на высоту $2.5 \mathrm{~mm}$. Масса всех запрессованных ЭНМ составляла $46 \mathrm{mg}$, плотность - $\rho_{c} \approx 1.2 \mathrm{~g} / \mathrm{cm}^{3}$. Учитывая массу и габариты запрессованного ЭНМ, можно было ожидать, что взрывчатые превращения в образцах могут происходить либо в режиме медленного горения, либо в режиме дефлаграции.

Схема облучения образца (ЭНМ) пучком полностью аналогична схеме, приведенной в работе [15] (рис. 1). В качестве электронного ускорителя использовалась установка ГКВИ-300 [16]. Колпачок с исследуемым ЭНМ устанавливался в стальное кольцо с внешним диаметром $30 \mathrm{~mm}$. Стальное кольцо 3, в котором находился колпачок 5 с ЭНМ 4, устанавливалось на стальную подложку 6 толщиной $2.2-2.5 \mathrm{~mm}$ и служило в качестве „Пластины-свидетеля“, на которой оставался или не оставался отпечаток от колпачка после того, как в образце происходили некие взрывчатые превращения. Иногда под пластину-свидетель устанавливался пьезокерамический датчик давления.

Длительность импульса тока на его полувысоте составляла 20-40 ns, средняя энергия электронов в пучке - $250 \mathrm{keV}$, расстояние между катодом и образцом $-4 \mathrm{~mm}$, диаметр пучка $-8 \mathrm{~mm}$. Все эксперименты проводились с отсечкой катодного факела путем установки фольги алюминиевой или титановой различной толщины. 


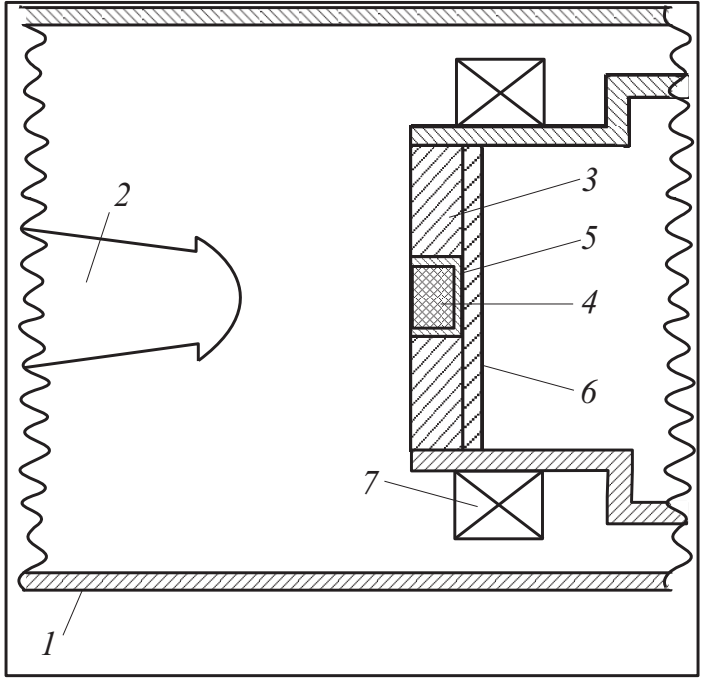

Рис. 1. Экспериментальная схема облучения пучком электронов образца: 1 - вакуумная камера, 2 - катод, 3 - стальное кольцо, 4 - ЭНМ, 5 - колпачок, 6 - подложка, 7 - пояс Роговского (измеритель тока).

Облучение образцов бета-частицами выполнено на бета-источнике БИС-20, изготовленного на основе радионуклидов ${ }_{38}^{90} \mathrm{Sr}+{ }_{39}^{90} \mathrm{Y}$ (стронций $90+$ иттрий 90) с активностью $9.5 \cdot 10^{10} \mathrm{~Bq}$. Диаметр рабочей поверхности $-20 \mathrm{~mm}$. Поток энергии ионизирующего излучения определен с помощью ферросульфатного дозиметра и рассчитывался по формуле

$$
E=\frac{\mathrm{C}_{\mathrm{Fe}^{+3}} \cdot V \cdot N_{0} \cdot 100}{G_{\mathrm{Fe}^{+3}} \cdot 6.24 \cdot 10^{11} \cdot 60 \cdot t}
$$

где $C_{\mathrm{Fe}^{+3}}$ - концентрация трехвалентного железа $\mathrm{Fe}^{+3}$; $V$ - объем облучаемого раствора в $\mathrm{ml} ; N_{0}$ - число Авогадро; $G_{\mathrm{Fe}^{+3}}=15.5 \mathrm{ion} / \mathrm{eV}$ - выход ионов $\mathrm{Fe}^{+3}$ в ферросульфатном дозиметре; $6.24 \cdot 10^{11}$ - переводной коэффициент из одной системы единиц в другую; $t-$ время облучения. В результате измерений и расчетов поток ионизирующего излучения от источника составляет $E=1640 \mathrm{erg} / \mathrm{s}$. Средняя энергия $\beta$-частиц составляла $0.54 \mathrm{MeV}$ для ${ }^{90} \mathrm{Sr}$ и $2.27 \mathrm{MeV}$ для ${ }^{90} \mathrm{Y}$. Мощность экспозиционной дозы рентгеновского излучения и тормозного $\gamma$-излучения на расстоянии $1 \mathrm{~m}$ составляет $2.5 \cdot 10^{-5} \mathrm{R} / \mathrm{s}$.

Облучение гамма-частицами выполнено на $\gamma$-установке К-120000, которая относится к мощным стационарным установкам сухого типа с подвижным облучателем. В гамма-установке используются кобальтовые источники типа ГИК-7-4 в количестве 60 штук. При распаде изотопа Кобальт-60 (с образованием стабильного изотопа Никель-60) происходит испускание квантов с энергией 1.1732 и $1.3325 \mathrm{MeV}$. Максимальная мощность дозы облучения на установке К-120000 равна $10 \mathrm{~Gy} / \mathrm{s}$, мощность дозы облучения в области однородного поля $-5 \mathrm{~Gy} / \mathrm{s}$. Значения дозы, получаемой образцами при облучении, определялись по данным специально проводимой аттестации. Установка К-120000 аттестована по мощности поглощенной дозы с помощью образцовых глюкозных дозиметров ДОГ-25/200. Погрешность измерения мощности поглощенной дозы составляет $10 \%$ при доверительной вероятности 0.95 .

\section{Результаты экспериментов с ВС-2}

Воздействие СЭП (с установкой алюминиевой фольги толщиной $20 \mu \mathrm{m})$ на необлученный состав ВС-2 приводило к полному выгоранию состава внутри колпачка, при этом отпечаток от колпачка на подложке отсутствовал, т.е. в данном случае инициирующего импульса было достаточно только для возбуждения медленного горения состава. При установке алюминиевой фольги толщиной $40 \mu \mathrm{m}$ зажигания состава не происходило.

В то же время воздействие СЭП через алюминиевую фольгу толщиной $40 \mu \mathrm{m}$ на облученные бета-частицами образцы при поглощенной дозе $9 \mathrm{kGy}$ через $\sim 24 \mathrm{~h}$ после облучения приводило к полному выгоранию состава, при этом на подложке наблюдался отпечаток от колпачка глубиной $40 \mu \mathrm{m}$ (рис. 2).

Воздействие СЭП через алюминиевую фольгу толщиной $60 \mu \mathrm{m}$ на облученные бета-частицами образцы при поглощенной дозе $9 \mathrm{kGy}$ через $\sim 24 \mathrm{~h}$ после облучения приводило к полному выгоранию состава, при этом отпечаток на подложке отсутствовал. Установка титановой фольги толщиной $50 \mu \mathrm{m}$ при поглощенной дозе $10 \mathrm{kGy}$ через $\sim 24 \mathrm{~h}$ после облучения приводила к отказам инициирования зажигания состава (во всех трех испытанных образцах). Отметим, что $50 \mu \mathrm{m}$ титановой фольги соответствует (по рассеивающей способности энергии электронов) $100 \mu \mathrm{m}$ алюминиевой фольги.

Увеличение поглощенной дозы до $28 \mathrm{kGy}$ через сутки после облучения приводило к полному выгоранию состава при транспортировании СЭП через титановую фольгу толщиной $50 \mu \mathrm{m}$, при этом глубина отпечатка на подложке составляла $\sim 30 \mu \mathrm{m}$. Дальнейшее увеличение поглощенной дозы до $34 \mathrm{kGy}$ через сутки после

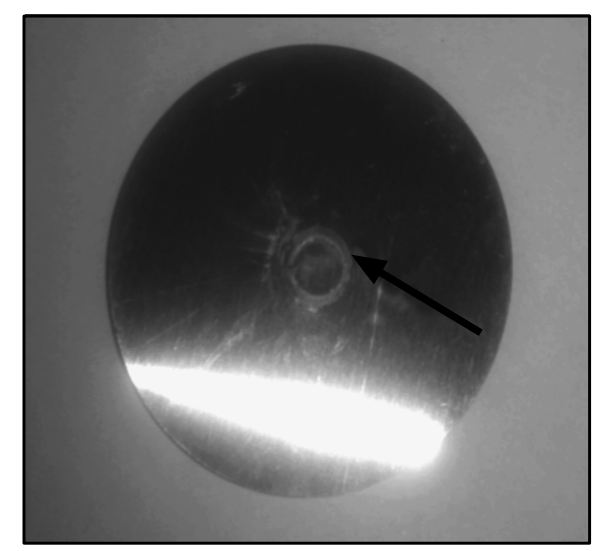

Pис. 2. Отпечаток (показан стрелкой) на подложке. 


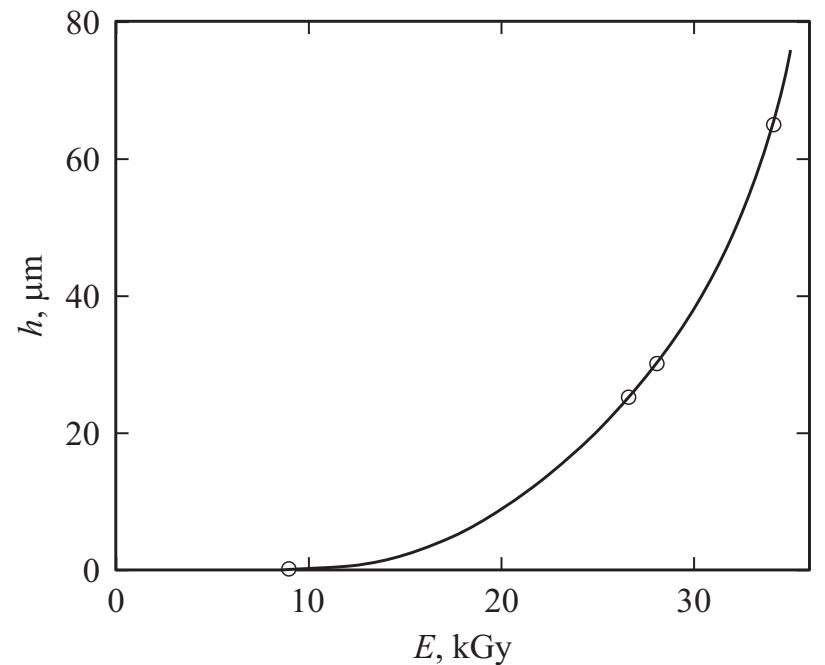

Рис. 3. Зависимость глубины отпечатка от поглощенной дозы облучения.

облучения приводило к полному выгоранию состава при транспортировании СЭП через титановую фольгу толщиной $50 \mu \mathrm{m}+20 \mu \mathrm{m}$ алюминиевой фольги, глубина отпечатка на подложке составляла $\sim 65 \mu \mathrm{m}$.

Дальнейшие исследования, связанные с длительностью хранения после облучения образцов ВС-2, показали, что при поглощенной дозе $26.5 \mathrm{kGy}$, при транспортировании СЭП через титановую фольгу толщиной $50 \mu \mathrm{m}$ происходит полное выгорание состава с одинаковым отпечатком на подложке глубиной $25 \mu \mathrm{m}$ как через один, два, шесть и восемь месяцев хранения соответственно облученных образцов. Зависимость глубины отпечатка от дозы облучения представлена на рис. 3.

Таким образом, на основе экспериментов с облученными бета-частицами образцами с составом ВС-2 можно сделать два предварительных вывода: 1) предварительное облучение состава ВС-2 приводит к усилению действия СЭП, при этом, чем больше поглощенная доза, тем выше чувствительность состава к действию СЭП; 2) эффект облучения сохраняется, по крайней мере, не менее восьми месяцев.

Предварительное облучение образцов ВС-2 гаммаквантами привело к следующим результатам. При поглощенной дозе $10 \mathrm{kGy}$ через $\sim 30 \mathrm{~h}$ после облучения и транспортировании СЭП через алюминиевую фольгу толщиной $60 \mu \mathrm{m}$ происходило полное выгорание состава и на подложке образовывался отпечаток от колпачка глубиной $55 \mu \mathrm{m}$. При поглощенной дозе $30 \mathrm{kGy}$ через $\sim 32 \mathrm{~h}$ после облучения при транспортировании СЭП через титановую фольгу толщиной $50 \mu \mathrm{m}+40 \mu \mathrm{m}$ алюминиевой фольги происходило полное выгорание состава, при этом отпечаток (во все трех экспериментах) на подложке отсутствовал. В целом, полученные результаты дают основание полагать, что облучение образцов ВC-2 гамма-квантами более эффективно по сравнению с облучением бета-частицами.

\section{Результаты экспериментов с композитом $\mathrm{NCP}+\mathrm{C}_{60}$}

В работе [15] было установлено, что образцы NCP без добавок фуллеритов, так и с их добавками при отсечке КФ под действием только сильноточного электронного пучка, не воспламенялись (в условиях энергетических параметров электронного пучка). Их зажигание происходило только при совокупном воздействии СЭП + КФ.

После предварительного облучения образцов с исследуемым энергонасыщенным композитом бета-частицами были получены результаты, которые приведены в таблице.

Полученные результаты свидетельствуют о том, что предварительное облучение $\beta$-частицами энергонасыщенного композита $\mathrm{NCP}+\mathrm{C}_{60}$ (диэлектрика) приводил к увеличению его чувствительности к действию СЭП, однако по сравнению с составом ВС-2 (полупроводника) эффективность облучения существенно ниже.

Предварительное облучение образцов $\mathrm{NCP}+\mathrm{C}_{60}$ гамма-квантами привело к следующим результатам. При поглощенной дозе $10 \mathrm{kGy}$ через $\sim 72 \mathrm{~h}$ после облучения и транспортировании СЭП через алюминиевую фольгу толщиной $20 \mu \mathrm{m}$ происходило полное выгорание состава, при этом отпечаток на стальной подложке отсутствовал. При поглощенной дозе $25 \mathrm{kGy}$ через $\sim 74 \mathrm{~h}$ после облучения и транспортировании СЭП через алюминиевую фольгу толщиной $40 \mu \mathrm{m}$ происходило полное выгорание состава, при этом на стальной подложке присутствовал отпечаток глубиной $25 \mu \mathrm{m}$. Таким образом, и в случае с энергонасыщенным композитом, как и с составом ВС-2, наблюдается бо́льшая эффективность облучения $\gamma$-квантами по сравнению с облучением $\beta$-частицами.

\section{Анализ результатов экспериментов}

Для анализа результатов всех вышеприведенных экспериментов были проведены исследования по влиянию толщины алюминиевой фольги на энергетические потери сильноточного электронного пучка. В результате была получена экспериментальная кривая изменения энергии пучка в зависимости от толщины фольги (рис. 4).

Полученные результаты экспериментов по изменению энергии пучка в зависимости от толщины алюминиевой фольги в совокупности с результатами экспериментов по воздействию СЭП на предварительно облученные образцы свидетельствуют о высокой эффективности облучения с точки зрения увеличения чувствительности к воздействию сильноточного электронного пучка наносекундной длительности. Так, для образцов ВС-2, поглотивших дозу излучения $28 \mathrm{kGy}$, энергию, необходимую для инициирования зажигания, удается снизить на 80\%. C чем же может быть связана столь высокая эффективность предварительного облучения? На наш взгляд существует, по крайней мере, три причины для обоих 
Результаты экспериментов с композитом $\mathrm{NCP}+\mathrm{C}_{60}$

\begin{tabular}{c|c|c|c|c|c}
\hline № & $\begin{array}{c}\text { Поглощенная } \\
\text { доза, } \\
\mathrm{kGy}\end{array}$ & $\begin{array}{c}\text { Толщина } \\
\text { фольги, } \\
\mu \mathrm{m}\end{array}$ & $\begin{array}{c}\text { Время хранения } \\
\text { образцов до } \\
\text { экспериментов }\end{array}$ & $\begin{array}{c}\text { Результаты } \\
\text { эксперимента }\end{array}$ & $\begin{array}{c}\text { Глубина } \\
\text { отпечатка, } \\
\mu \mathrm{m}\end{array}$ \\
\hline 1 & 10 & 20 & $24 \mathrm{~h}$ & - & - \\
2 & 25 & 20 & $48 \mathrm{~h}$ & + & - \\
3 & 35 & 20 & $48 \mathrm{~h}$ & + & 30 \\
5 & 50 & 20 & 3 месяца & + & 30 \\
5
\end{tabular}

Примечание. (-) означает отсутствие воспламенения, $(+)$ - полное выгорание композита. В экспериментах после трех и шести месяцев хранения образцов пьезокерамический датчик давления фиксировал сигнал.

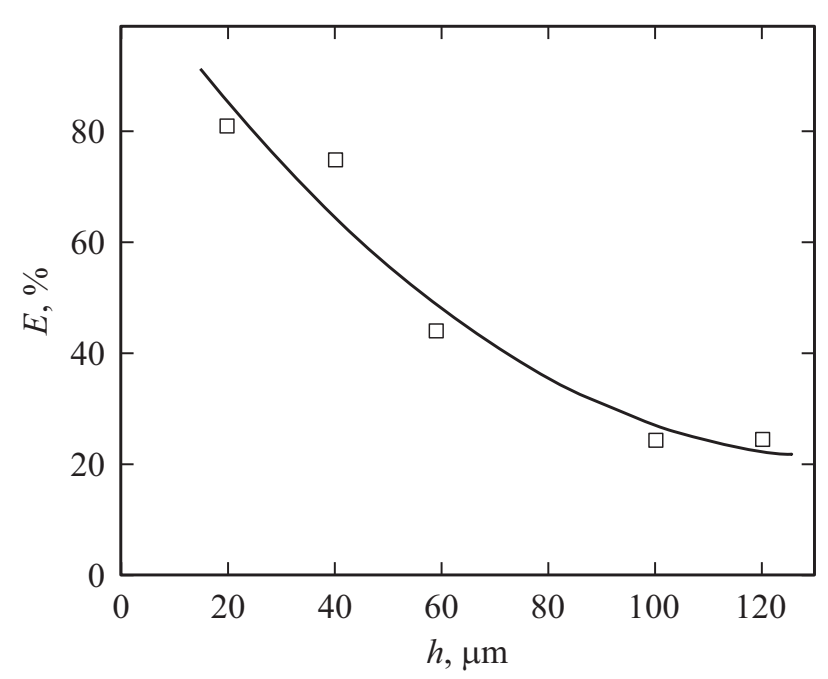

Рис. 4. Изменение энергии пучка в зависимости от толщины алюминиевой фольги.

составов, обусловливающие полученный эффект, и одна дополнительная (четвертая) причина для состава ВС-2.

1.В частицах (зернах) ЭНМ всегда присутствуют дефекты в виде вакансий, что создает в диэлектриках и полупроводниках, которыми являются ЭНМ, дополнительные энергетические уровни в запрещенной зоне. Именно на этих уровнях и могут локализоваться избыточные электроны, привнесенные $\beta$-частицами или $\gamma$-квантами. Действие СЭП на облученные энергонасыщенные материалы приводит к освобождению захваченных электронов, т. е. в приповерхностном слое появляется достаточно большое количество свободных носителей тока. ЭНМ (диэлектрик или полупроводник) становится в этом случае проводником (радиоэлектриком), между анодом и катодом возникает электрический разряд, а в образце (заряде) (запрессованном в колпачок) возникают многочисленные разрядные каналы [17], заполненные плазмой. В каналах сосредоточивается высокая концентрация энергии, приводящая к резкому повышению давления и температуры $\left(\sim 10^{4} \mathrm{~K}\right)$, под действием которых и происходит инициирование энергонасыщенного состава (или композита).
2.Привнесенные в процессе предварительного облучения избыточные электроны повышают количество свободных электронов в веществе и уменьшают ширину запрещенной зоны, вплоть до того, что вещество приобретает проводящие или полупроводящие свойства. В этом случае внутри энергонасыщенного соединения может произойти изменение параметров теплопередачи, что приведет к ускорению процесса горения между очагами (горячими точками), возникающими в образце при воздействии СЭП, и, как следствие, привести к возбуждению реакции во всем запрессованном заряде (образце). Данное положение требует пояснения.

Прежде всего остановимся на очаговом механизме возбуждения реакции ВП в образце под действием СЭП. В силу того, что сильноточный электронный пучок не является моноэнергетичным, его воздействие на различные участки поверхности образца неоднородно как в пространстве, так и во времени. Кроме того, необходимо отметить, что, если в необлученных образцах основные потери энергии пучка связаны с ионизацией среды, то в предварительно облученных - часть потерь обусловлена электрон-ионной рекомбинацией, что, безусловно, усиливает энергетическую неоднородность облучаемого вещества. В результате в заряде возникает система мезоскопических очагов, от которых процесс горения может разойтись по всему образцу. В нашем случае можно полагать, что первоначальными очагами горения являются отдельные зерна, которые вследствие структурной неоднородности оказались наиболее восприимчивы к действию высокоэнергетичных электронов пучка. Горение системы изолированных очагов (как крайний случай - одного очага) может либо затухнуть, если энергия очага окажется меньше критического, либо перейти в горение всего заряда или (при определенных условиях) в более высокий режим взрывчатого превращения, если энергия первичных очагов (очага) будет больше критической [18]. При некоторой концентрации первичных очагов волны реакции от отдельных очагов будут объединяться, образуя сплошную область реакции. В этом случае возможно воспламенение заряда взрывчатого вещества от первичных очагов, даже если их энергия будет существенно меньше критической, т.е. существует некоторая критическая концентрация 
очагов, которая зависит от их энергии, выше которой происходит воспламенение всего заряда прессованного порошкообразного ЭНМ. Эта критическая концентрация тем меньше, чем ближе энергия очагов к критической. Если энергия очага много больше критической, то воспламенение возможно даже от одиночного очага. Отметим, что на существенное влияние фактора критической концентрации очагов воспламенения указывалось в работах $[19,20]$.

Для оценки влияния критической концентрации первоначально воспламенившихся зерен воспользуемся оценкой характерного макроскопического времени реакции, т.е. времени процесса превращения ЭНМ в продукты горения - среднего времени смыкания волн горения [20]

$$
t_{r} \approx r / u_{f} \approx n^{-1 / 3} / u_{f}
$$

где $r$ - характерное расстояние между очагами воспламенения, $u_{f}-$ скорость горения, $n-$ концентрация очагов воспламенения.

Оценим параметры, стоящие в правой части соотношения (1). Поскольку в проводящих и полупроводящих веществах резко возрастает значимость электронной составляющей коэффициента теплопроводности [21], то скорость горения начинает зависеть от ширины запрещенной зоны: чем меньше ширина запрещенной зоны, тем выше скорость горения. Данное положение следует из следующих формальных соотношений. Общую теплопроводность полупроводника (пренебрегая биполярной и фотонной теплопроводностью) можно представить в виде

$$
\lambda=\lambda_{r}+\lambda_{e l}
$$

где $\lambda_{r}$ - решеточная (фононная) составляющая общей теплопроводности, $\lambda_{e l}$ - электронная составляющая теплопроводности. Не заботясь о большой точности, можно полагать, что $\lambda \approx 2 \lambda_{e l}$. В соответствии с законом Видемана-Франца и с учетом зависимости собственной проводимости полупроводника $\sigma$ от температуры [22] электронную теплопроводность можно представить в виде

$$
\lambda_{e l}=L T \sigma_{0} e^{-\varepsilon_{g} / 2 k T} .
$$

Здесь $L-$ число Лоренца, $k$ - постоянная Больцмана, $T$ - температура, $\varepsilon_{g}$ - ширина запрещенной зоны, $\sigma_{0}$ - константа.

Таким образом, чем ниже ширина запрещенной зоны, тем выше коэффициент теплопроводности вещества. В то же время значение скорости горения $u_{f}$ можно выразить соотношением

$$
u_{f}=\alpha\left(\frac{a}{t_{r}}\right)^{0.5}
$$

где $a=\lambda / \rho c-$ коэффициент температуропроводности, $\rho$ - плотность вещества, $c-$ его теплоемкость, $t_{r}$ - характерное время реакции, $\alpha-$ некая константа.
А именно из (2)-(4) мы получили доказательство вышеуказанного вывода о соотношении между скоростью горения и шириной запрещенной зоны.

Очевидно, что концентрация очагов воспламенения пропорциональна объему вещества, в котором произошло поглощение как предварительного ионизирующего облучения, так и электронов импульсного пучка:

$$
n \sim r^{-3} \sim \frac{\pi}{4} d_{0}^{2} h_{e f f},
$$

где $d_{0}$ - диаметр образца (вернее - диаметр пучка электронов, но в нашем случае диаметр пучка электронов больше диаметра образца), $h_{e f f}-$ некая эффективная зона поглощения.

Для характерного времени реакции поставим условие

$$
t_{r} \rightarrow t_{0}
$$

Здесь $t_{0}$ - длительность импульса облучения СЭП. Из (1), (4) и (5) следует, что условие (6) будет выполняться с большим успехом при условиях

$$
\lambda \rightarrow \lambda_{\max }, n \rightarrow n_{\max }
$$

Условия (7) в совокупности с вышеприведенными оценками объясняют полученные экспериментальные результаты: 1) чем больше поглощенная доза, тем выше чувствительность состава к действию СЭП; 2) эффективность облучения $\gamma$-квантами образцов ЭНМ выше по сравнению с облучением $\beta$-частицами. В первом случае, очевидно, бо́льшая доза облучения приводит к большему количеству свободных электронов и, как следствие, к большей проводимости и теплопроводности. Для второго случая длина пробега $\gamma$-квантов существенно больше длины пробега $\beta$-частиц, следовательно, $h_{e f f}$ для $\gamma$-квантов существенно больше, чем $h_{e f f}$ для $\beta$-частиц, и тем самым концентрация очагов воспламенения в случае облучения $\gamma$-квантами существенно выше концентрации очагов воспламенения при облучении $\beta$-частицами.

3. Предварительное ионизирующее облучение энергонасыщенных составов приводит к разупорядочиванию и разрыхлению структуры составов и деструкции молекул, что способствует большей проникающей способности СЭП [16] и тем самым к увеличению концентрации очагов воспламенения и соответственно к увеличению чувствительности составов к воздействию СЭП.

4. При предварительном облучении $\beta$-частицами или $\gamma$-квантами энергонасыщенного состава ВC-2 происходит аномально высокий радиационно-химический выход парамагнитных продуктов ионизации [3,23] (которые нами не идентифицированы), что резко увеличивает ускорение гетерогенно-каталитической реакции в поле излучения сильноточного электронного пучка и в целом резко увеличивает чувствительность ЭНМ к воздействию СЭП. 


\section{Заключение}

По результатам проведенных исследований можно сформулировать следующие выводы.

1. Предварительное облучение потоком $\beta$-частиц или $\gamma$-квантами энергонасыщенных материалов приводит к существенному увеличению их чувствительности к воздействию СЭП наносекундной длительности. В этом случае возможно инициирование ЭНМ без дополнительного воздействия катодного факела.

2. Чем выше предварительно поглощенная ЭНМ доза, тем выше его чувствительность к воздействию СЭП.

3. Предварительное облучение энергонасыщенных составов $\gamma$-квантами более эффективно по сравнению с облучением $\beta$-частицами, что обусловлено большей проникающей способностью $\gamma$-квантов в вещество.

4. Эффект облучения образцов, связанный с повышением их чувствительности к воздействию сильноточного электронного пучка наносекундной длительности, сохраняется по крайней мере не менее 8 месяцев.

\section{Список литературы}

[1] Струнин В.А., Манелис Г.Б., Пономарев А.Н., Тальрозе В.Л. // Физика горения и взрыва. 1968. № 4. С. 584-590. [Strunin V.A., Manelis G.B., Ponomarev A.N. et al. // Combust Explos Shock Waves. 1968 Vol. 4. N 4. P. 339-342. https://doi.org/10.1007/BF00742577]

[2] Ададуров Г.А., Карпухин И.А., Мальцев В.М., Тесёлкин B.A. О свойствах перхлората аммония, подвергнутого предварительному активированию ударными волнами и $\gamma$-облучением // Тез. докл. Всесоюз. симпоз. по импульсным давлениям. М.: Изд-во ВНИИФТРИ, 1973. С. 89-90.

[3] Рябых С.М., Пак В.Х., Якубик Д.Г. // Изв. вузов. Физика. 2011. № 1/3. C. 194-197.

[4] Коптелов А.А., Милехин Ю.М. // Физика горения и взрыва. 2007. Т. 43. № 6. С. 69-74. [Koptelov A.A., Milekhin Yu.M. // Combust Explos Shock Waves. 2007. Vol. 43. N 6. P. 682-687. https://doi.org/10.1007/s10573-0070091-5]

[5] Головин Ю.И., Иванова М.А., Лопатин Д.В., Николаев Р.К., Умрихин А.В. // ФТТ. 2004. Т. 46. Вып. 11. С. 2109 2110. [Golovin Y.I., Ivanova M.A., Lopatin D.V. et al. // Phys. Solid State. 2004. Vol. 46. N 11. P. 2183-2184. https://doi.org/10.1134/1.1825568]

[6] Савенков Г.Г., Морозов В.А., Семашкин Г.В., Соловьев В.А., Брагин В.А. // Известия СПбГТИ (ТУ). 2013. № 21 (47). C. $80-83$.

[7] Савенков Г.Г., Морозов В.А., Лукин А.А., Брагин В.А., Семашкин Г.В. // Письма в ЖТФ. 2014. Т. 40. Вып. 6. C. 50-58. [Savenkov G.G., Morozov V.A., Lukin A.A. et al. // Tech. Phys. Lett. 2014. Vol. 40. N 3. P. 256-259. https://doi.org/10.1134/S1063785014030250]

[8] Алукер Э.Д., Алукер Д.Э., Нурмухаметов Д.Р., Швайко В.Н. // Физика горения и взрыва. 2006. T. 42. № 2. C. 116-120. [Aluker É.D., Aluker D.É., Nurmukhametov D.R. et al. // Combust Explos Shock Waves. 2006. Vol. 42. N 2. P. 227-230.

https://doi.org/10.1007/s10573-006-0043-5]
[9] Савенков Г.Г., Морозов В.А., Персинен А.А., Оськин И.А., Брагин В.А., Лукин А.А. // Письма в ЖТФ. 2016. T. 42. Вып. 17. C. 28-33. [Savenkov G.G., Morozov V.A., Persinen A.A. et al. // Tech. Phys. Lett. 2016. Vol. 42 N 9. P. 895-897. https://doi.org/10.1134/S106378501609008X]

[10] Мещеряков Ю.И., Морозов В.А. // ЖТФ. 1979. Т. 49. Вып. 9. С. 1982-1986.

[11] Morozov V.A., Lukin A.A., Savenkov G.G., Oskin I.A. // Intern. Conf. „Stability and Control Processes" in Memory of V.I. Zubov (SCP), St. Petersburg, 2015. https://doi.org/177-179. 10.1109/SCP.2015.7342084

[12] Электреты / Под ред. Г. Сесслера. М.: Мир, 1983. 487 с.

[13] Смолянский А.С., Соколов А.П., Тарабан В.Б., Жданов Г.С. и др. // Высокомолекулярные соединения. Сер. А. 1991. T. 33. № 12. C. 2555-2561.

[14] Ардашников С.Н., Гольдин С.М., Николаев А.В. и др. Защита от радиоактивных излучений. М.: Металлургиздат, $1961.420 \mathrm{c}$.

[15] Савенков Г.Г., Морозов В.А., Илюшин М.А., Оськин И.А., Брагин В.А. // ЖТФ. 2017. Т. 87. Вып. 11. С. 1701-1706. https://doi.org/10.21883/JTF.2017.11.45133.2227

[16] Морозов В.А., Савенков Г.Г., Брагин В.А. идр. // ЖТФ. 2012. Т. 82. Вып. 5. С. 129-134. [Morozov V.A., Savenkov G.G., Bragin V.A. et al. // Tech. Phys. 2012. Vol. 57. N 5. P. 706-710. https://doi.org/10.1134/S1063784212050210]

[17] Новиков Г.В., Гриднев А.В., Чиванов А.В., Федоров В.А. // Вестник ТГУ. 2010. Т. 15. № 3. С. 1238-1241.

[18] Рашковский С.А., Савенков Г.Г. // Письма в ЖТФ. 2014. T. 40. Вып. 11. C. 73-79. [Rashkovskii S.A., Savenkov G.G. // Tech. Phys. Lett. 2014. Vol. 40. N 6. P. 485-487. https://doi.org/10.1134/S1063785014060108]

[19] Лобанов В.Ф. // Физика горения и взрыва. 1980. Т. 26. № 6. C. $113-116$.

[20] Гребенкин К.Ф. // Физика горения и взрыва. 2009. Т. 45. № 1. C. 89-99. [Grebenkin K.F. // Combust Explos Shock Waves. 2009. Vol. 45. N 1. P. 78-87. https://doi.org/10.1007/s10573-009-0011-y]

[21] Стильбас Л.С. Физика полупроводников. М.: Советское радио, 1967. $452 \mathrm{c}$.

[22] Зегря Г.Г., Перель В.И. Основы физики полупроводников. М.: Физматлит, 2009. $336 \mathrm{c.}$

[23] Гладкий А.Ю., Аристов Ю.И. // Письма в ЖТФ. 1991. Т. 17. Вып. 24. С. 49-52. 